\title{
3,6-Carbazole vs 2,7-carbazole: A comparative study of hole-transporting polymeric materials for inorganic-organic hybrid perovskite solar cells
}

\author{
Wei $\mathrm{Li}^{1}$, Munechika Otsuka ${ }^{2}$, Takehito Kato ${ }^{*}$, Yang Wang ${ }^{1}$, Takehiko Mori ${ }^{1}$ \\ and Tsuyoshi Michinobu*1
}

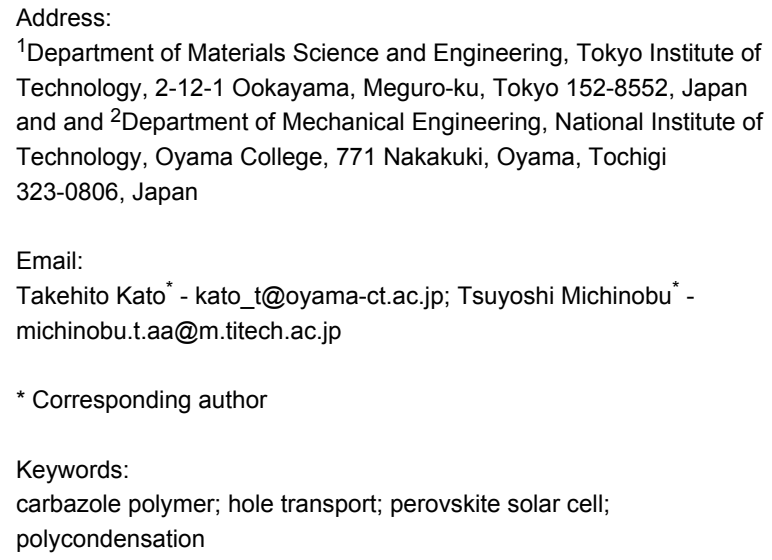

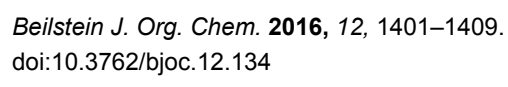

\begin{abstract}
The ever increasing demand for clean energy has encouraged researchers to intensively investigate environmentally friendly photovoltaic devices. Inorganic-organic hybrid perovskite solar cells (PSCs) are very promising due to their potentials of easy fabrication processes and high power conversion efficiencies (PCEs). Designing hole-transporting materials (HTMs) is one of the key factors in achieving the high PCEs of PSCs. We now report the synthesis of two types of carbazole-based polymers, namely 3,6Cbz-EDOT and 2,7-Cbz-EDOT, by Stille polycondensation. Despite the same chemical composition, 3,6-Cbz-EDOT and 2,7-CbzEDOT displayed different optical and electrochemical properties due to the different connectivity mode of the carbazole unit. Therefore, their performances as hole-transporting polymeric materials in the PSCs were also different. The device based on 2,7Cbz-EDOT showed better photovoltaic properties with the PCE of 4.47\% than that based on 3,6-Cbz-EDOT. This could be due to its more suitable highest occupied molecular orbital (HOMO) level and higher hole mobility.
\end{abstract}

\section{Introduction}

Inorganic-organic hybrid perovskite solar cells (PSCs) have recently received significant attention due to their remarkably high power convention efficiencies (PCEs). After the seminal study reported by Miyasaka et al. in 2009 with the PCE of $4 \%$
[1], some key improvements have been made in designing device structures and fabrication methods, and the PCE of the PSCs rapidly increased to $>20 \%$ [2-5]. Compared to the conventional organic photovoltaics and dye-sensitized solar 
cells (DSSCs), PSCs benefit from a broad light absorption and high carrier diffusion length as excellent features of the perovskite materials. The development of efficient hole-transporting materials (HTMs), which extract a hole from the perovskite layer and transport it to the anode, is also significant for the further improvement of the PSC performances. So far, 2,2',7,7'-tetrakis( $N, N$-di( $p$-methoxyphenyl)amino)-9,9-spirobifluorene (spiro-OMeTAD) is regarded as the most conventional solid state hole transporter for the PSCs [6-10]. Despite the high PCEs conferred by this hole transporting layer, spiro-OMeTAD has several limitations, such as its complicated multistep synthesis, low hole mobility in its pristine form, and expensive fabrication costs of the PSCs due to the sublimable small molecule. Accordingly, solution-processable hole-transporting polymers with simple structures have also been pursued as HTMs in the PSCs. Common p-type semiconducting polymers, such as poly(3-hexylthiophene) (P3HT), and the state-of-the-art narrow band gap polymers, such as poly[2,5-bis(2-decyldodecyl)pyrrolo[3,4-c]pyrrole-1,4(2H,5H)-dione-(E)-1,2-di(2,2'-bithiophen-5-yl)ethane (PDPPDBTE), were successfully applied to the HTM in the PSCs $[11,12]$. Among them, the poly(triarylamine) derivatives are currently some of the best polymeric hole-transporting materials for the PSCs [13].

Carbazole (Cbz)-based conjugated polymers are widely used as active photo- and semiconducting materials in a variety of organic electronics due to their tunable optical and electrical properties [14-21]. For example, the 3,6-positions of the carbazole readily react with various electrophiles, and accordingly, many types of linear and hyperbranched poly(3,6carbazole) derivatives have been reported to show potent redox activities and nonlinear optical or photorefractive properties [22-24]. These features were also applied to organic light-emitting diodes (OLEDs) [25]. In contrast, the poly(2,7-carbazole) derivatives appeared after the pioneering synthetic studies of the 2,7-dihalogeno-carbazole monomers [26,27]. A series of 2,7carbazole-based copolymers were synthesized, and most of them showed better semiconducting properties in organic field effect transistors (OFETs), bulk-heterojunction (BHJ) solar cells, thermoelectric and electrical memory devices as compared to the counter 3,6-carbazole-based polymers [28-36]. However, this structural relationship between the 3,6-carbazole and 2,7-carbazole has not yet been eluciated in the PSCs because of the emerging new devices.

In this study, we designed two carbazole-based hole-transporting polymers with different connectivity patterns. In order to enhance the electron-donating properties, the carbazole monomers were copolymerized with the electron-rich 3,4-ethylenedioxythiophene (EDOT) unit by Stille polycondensation. The energy levels and hole mobilities of the resulting carbazole copolymers, namely 3,6-Cbz-EDOT and 2,7-Cbz-EDOT, were estimated from the optical and electrochemical measurements and OFET performances, respectively. Finally, they were applied as the hole-transporting layer of the PSCs, and the photovoltaic properties of both devices were compared. The device based on 2,7-Cbz-EDOT displayed a higher PCE of $4.47 \%$ than that based on 3,6-Cbz-EDOT, which could be explained by their energy levels and hole mobilities.

\section{Results and Discussion \\ Polymer synthesis}

Carbazole copolymers with different connectivity patterns were synthesized by the Stille polycondensation between the bis(tri$n$-butylstannyl)carbazole monomers and 2,5-dibromo-EDOT (Scheme 1). We very recently reported the synthesis of the same polymer structures by the microwave-assisted direct arylation polycondensation, but it should be noted that the soluble

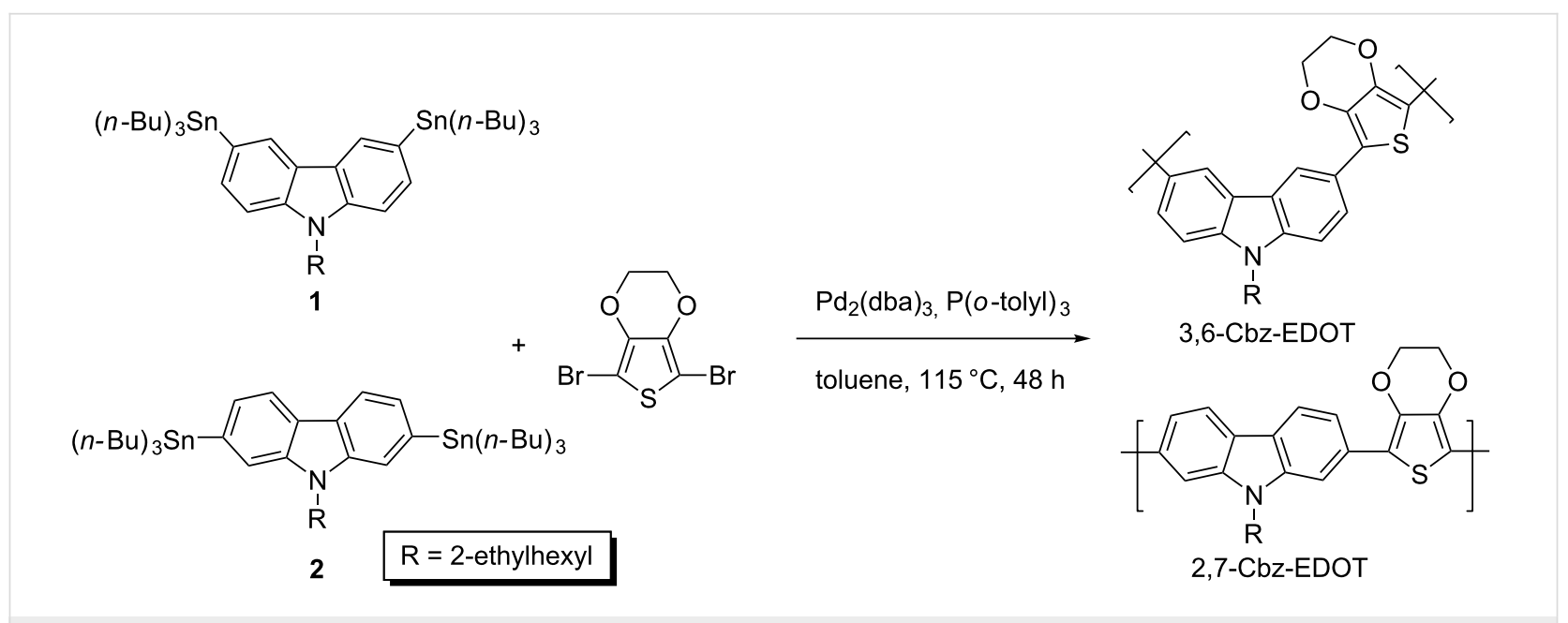

Scheme 1: Synthesis of 3,6-Cbz-EDOT and 2,7-Cbz-EDOT by Stille polycondensation. 
2,7-Cbz-EDOT could not be obtained due to undesired side reactions [37]. In contrast, the conventional Stille polycondensation afforded the desired linear polymers without any side reactions. The number-averaged molecular weight $\left(M_{\mathrm{n}}\right)$ and polydispersity indices $\left(M_{\mathrm{w}} / M_{\mathrm{n}}\right)$, determined by GPC using THF as the eluent, were $2.0 \mathrm{~kg} \mathrm{~mol}^{-1}(n \sim 5)$ and 1.5 for $3,6-\mathrm{Cbz}^{-}$ EDOT and $3.0 \mathrm{~kg} \mathrm{~mol}^{-1}(n \sim 7)$ and 1.4 for 2,7-Cbz-EDOT, respectively. The polymer structures were characterized by ${ }^{1} \mathrm{H}$ NMR and FTIR spectroscopies (Figure S1, Supporting Information File 1). The ${ }^{1} \mathrm{H}$ NMR spectra revealed the ethylene groups of EDOT at ca. $4.2 \mathrm{ppm}$ and the methylene group directly attached to the nitrogen atom of the carbazole at ca. 4.4 ppm, respectively, suggesting the successful copolymerization. Both polymers showed an explicit difference in their chemical shift values ascribed to the carbazole units due to the different connectivity patterns. In contrast, the IR spectra of the polymers were almost the same.

\section{Optical and electrochemical properties}

The UV-vis absorption spectra were employed to evaluate the optical properties of 3,6-Cbz-EDOT and 2,7-Cbz-EDOT. The spectra were measured in $\mathrm{CH}_{2} \mathrm{Cl}_{2}$ and in thin films (spin-coated on an ITO glass). The absorption maximum $\left(\lambda_{\max }\right)$ of $3,6-\mathrm{Cbz}-$ EDOT in $\mathrm{CH}_{2} \mathrm{Cl}_{2}$ was $362 \mathrm{~nm}$, whereas the thin film showed the bathochromically-shifted $\lambda_{\max }$ at $374 \mathrm{~nm}$ (Figure 1a). Compared to 3,6-Cbz-EDOT, 2,7-Cbz-EDOT showed a lower energy absorption in both the solution and thin film states $\left(\lambda_{\max }=435 \mathrm{~nm}\right.$ in $\mathrm{CH}_{2} \mathrm{Cl}_{2} ; \lambda_{\max }=443 \mathrm{~nm}$ in the thin film), which is consistent with previous reports [26]. The red shifts in the absorption spectra from the solution to thin film states implied the presence of strong intermolecular interactions between the polymer backbones.
Cyclic voltammetry $(\mathrm{CV})$ of the polymer thin films was measured in $\mathrm{CH}_{3} \mathrm{CN}$ with $0.1 \mathrm{M}\left(n-\mathrm{C}_{4} \mathrm{H}_{9}\right)_{4} \mathrm{NPF}_{6}$ as the supporting electrolyte at $20{ }^{\circ} \mathrm{C}$. Both polymers displayed irreversible oxidation peaks in the measurement range (Figure 1b). 3,6-CbzEDOT exhibited the onset oxidation potential ( $\left.E_{\text {ox,onset }}\right)$ at $0.38 \mathrm{~V}$ (vs Ag/ $/ \mathrm{Ag}^{+}$), whereas the $E_{\text {ox,onset }}$ of 2,7-Cbz-EDOT was slightly higher $(0.50 \mathrm{~V})$. This difference can also be explained by the different connectivity pattern between the two polymers. The linkage through the 3,6-positions of the carbazole unit forms a linear conjugation between the nitrogen atoms, which facilitates the electron removal from the conjugated main chain. In contrast, the nitrogen atoms through the 2,7-linked carbazoles are classified as a formal cross-conjugated structure [38].

As an efficient HTM for the PSCs, p-type polymers should have a good energy balance with the perovskite layer [39]. Most importantly, the highest occupied molecular orbital (HOMO) energy level should be close to the valence band of the perovskite. The HOMO levels of 3,6-Cbz-EDOT and 2,7-CbzEDOT were calculated according to Equation 1:

$$
E_{\mathrm{HOMO}}=-\left(E_{\mathrm{ox}, \text { onset }}+4.80-\varphi_{\mathrm{Fc} / \mathrm{Fc}+}\right)[\mathrm{eV}]
$$

where $\varphi_{\mathrm{Fc} / \mathrm{Fc}+}$ is the redox potential of the ferrocene/ferrocenium $\left(\mathrm{Fc} / \mathrm{Fc}^{+}\right)$couple measured under the same conditions (in this case, $0.09 \mathrm{~V}$ vs the $\mathrm{Ag} / \mathrm{Ag}^{+}$electrode). 2,7-Cbz-EDOT has a deeper HOMO level than 3,6-Cbz-EDOT. This was also the case for the lowest unoccupied molecular orbital (LUMO) levels, which were calculated from the HOMO levels and optical band gaps. All the data are listed in Table 1.
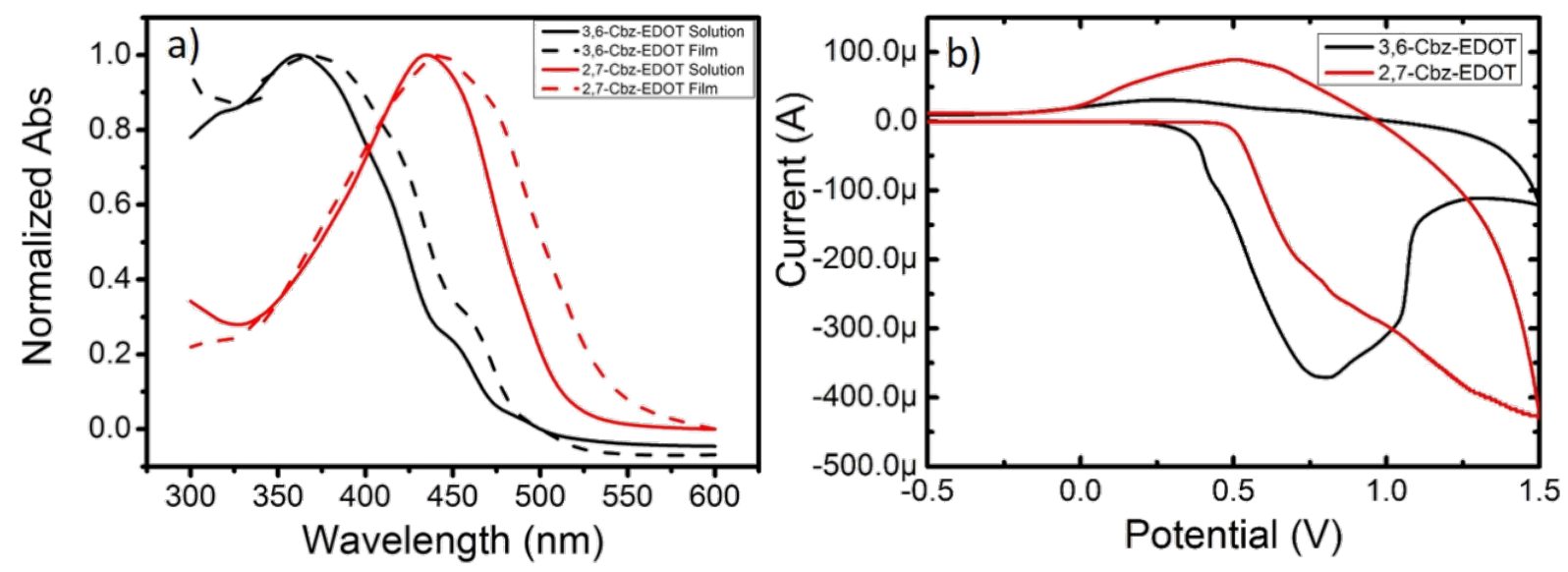

Figure 1: (a) Normalized UV-vis absorption of Cbz-EDOT polymers in $\mathrm{CH}_{2} \mathrm{Cl}_{2}$ measured at $10^{-5} \mathrm{M}$ repeat unit ${ }^{-1}$ and in thin films and (b) cyclic voltammetry of Cbz-EDOT polymer films on glassy carbon electrode, measured in $\mathrm{CH}_{3} \mathrm{CN}$ with $0.1 \mathrm{M}\left(n-\mathrm{C}_{4} \mathrm{H}_{9}\right)_{4} \mathrm{NPF}_{6}$ at the scan rate of $0.1 \mathrm{~V} \mathrm{~s}{ }^{-1}$ under flowing nitrogen. 


\begin{tabular}{|c|c|c|c|c|c|c|}
\hline Polymer & $\begin{array}{c}\lambda_{\text {onset }} \\
(\mathrm{nm})\end{array}$ & $\begin{array}{l}\text { Band gap } \\
(\mathrm{eV})^{\mathrm{b}}\end{array}$ & $\begin{array}{c}E_{\text {ox,onset }} \\
(\mathrm{V})^{\mathrm{C}}\end{array}$ & $\begin{array}{l}\text { HOMO } \\
(e V)^{d}\end{array}$ & $\begin{array}{l}\text { LUMO } \\
(\mathrm{eV})^{\mathrm{e}}\end{array}$ & $\begin{array}{l}\text { Hole mobility } \\
\left(\mathrm{cm}^{2} V^{-1} \mathrm{~s}^{-1}\right)^{f}\end{array}$ \\
\hline 3,6-Cbz-EDOT & 480 & 2.58 & 0.38 & -5.09 & -2.50 & $3.5 \times 10^{-7}$ \\
\hline 2,7-Cbz-EDOT & 536 & 2.31 & 0.50 & -5.21 & -2.90 & $5.1 \times 10^{-6}$ \\
\hline
\end{tabular}

${ }^{\mathrm{a}}$ In the thin film states. ${ }^{\mathrm{b}}$ Calculated from the $\lambda_{\text {onset }}\left(1240 / \lambda_{\text {onset }}\right) .{ }^{\mathrm{c}} \mathrm{Vs} \mathrm{Ag} / \mathrm{Ag}^{+\mathrm{d}}$ Calculated from $E_{\mathrm{Ox}, \mathrm{onset}}$ and $\varphi_{\mathrm{Fc} / \mathrm{Fc}+.}{ }^{\mathrm{e} C a l c u l a t e d}$ from the HOMO levels and optical band gaps. 'Determined from the OEFT performances.

The carrier mobilities of the HTMs are some of the important parameters that determine the PSC performances. In order to elucidate the charge-transporting properties of the Cbz-EDOT polymers, top-contact/bottom-gate type OFET devices were fabricated, and the transistor performances were initially evaluated in air (for details see Supporting Information File 1). Both Cbz-EDOT polymers showed a p-type unipolar behavior during the measurements (Figure S2, Supporting Information File 1). Although the hole mobilities of both polymers were disappointedly low $\left(<10^{-5} \mathrm{~cm}^{2} \mathrm{~V}^{-1} \mathrm{~s}^{-1}\right)$ probably due to the unoptimized annealing conditions, the data clearly suggested that $2,7-\mathrm{Cbz}-$ EDOT has a hole mobilitiy one-order higher than 3,6-CbzEDOT (Table 1). This result is also consistent with the reported mobilities of other carbazole-based semiconducting polymers [40,41].

\section{Photovoltaic performances}

It was shown that the HOMO level $(-5.21 \mathrm{eV})$ of 2,7-CbzEDOT is deeper than that $(-5.09 \mathrm{eV})$ of $3,6-\mathrm{Cbz}-\mathrm{EDOT}$. The former value is comparable to that $(-5.20 \mathrm{eV})$ of P3HT and closer to the valence band $(-5.45 \mathrm{eV})$ of the perovskite layer employed in this study. Accordingly, this carbazole polymer (2,7-Cbz-EDOT) is expected to be a better HTM in the PSCs as compared to 3,6-Cbz-EDOT. In order to evaluate this theory, PSCs with the Cbz-EDOT hole-transporting layer were fabri- cated, and the photovoltaic properties were compared. The device based on P3HT was also fabricated as the control sample [42]. The device structure is $\mathrm{FTO} / \mathrm{TiO}_{2} /$ perovskite $\left(\mathrm{CH}_{3} \mathrm{NH}_{3} \mathrm{PbI}_{3}\right) / \mathrm{Cbz}$-EDOT (or P3HT)/Au, and the energy level diagram of the materials used in the devices is depicted in Figure 2.

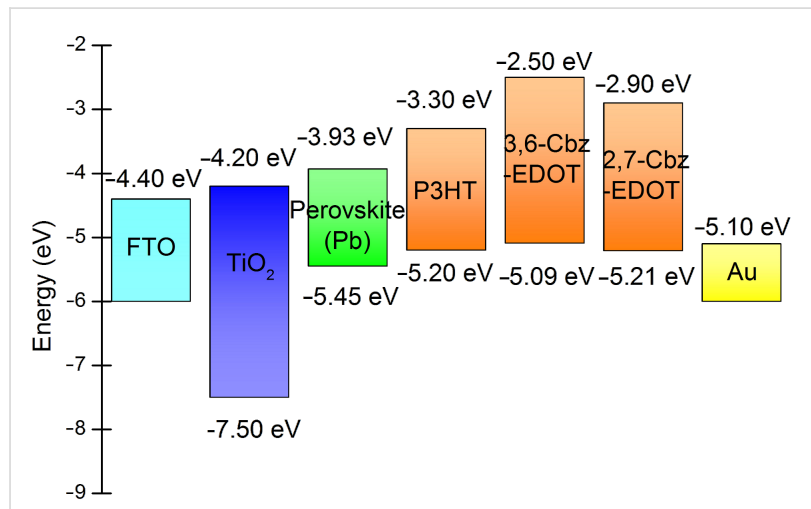

Figure 2: Energy level diagram of PSC components including $\mathrm{P} 3 \mathrm{HT}$, 3,6-Cbz-EDOT, and 2,7-Cbz-EDOT.

Figure 3a shows the current density-voltage $(J-V)$ curves for the devices based on 3,6-Cbz-EDOT, 2,7-Cbz-EDOT, and $\mathrm{P} 3 \mathrm{HT}$. The device performance parameters are summarized in
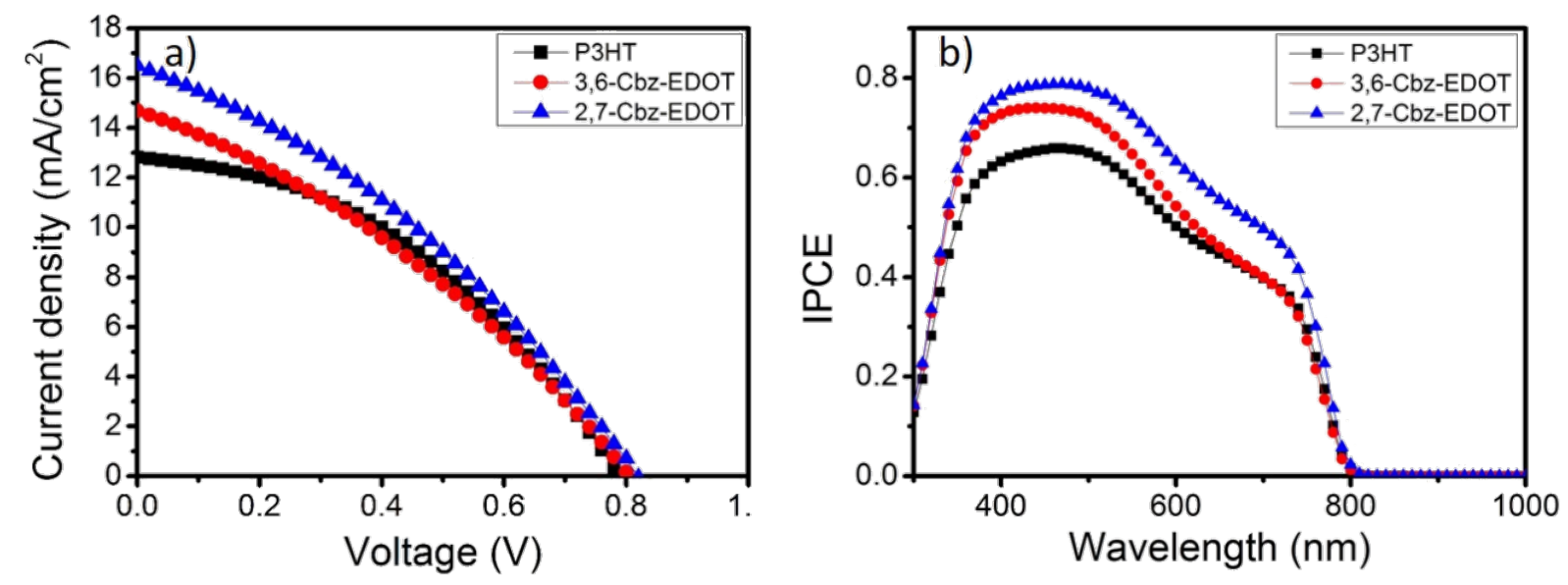

Figure 3: (a) Current density-voltage curves and (b) incident photon to current conversion efficiency (IPCE) spectra for PSCs with different HTMs under AM1.5G illumination at $100 \mathrm{~mW} \mathrm{~cm}^{-2}$. 
Table 2. Among the three devices, the device based on 2,7-CbzEDOT displayed the highest power conversion efficiency (PCE) of $4.47 \%$ with a short-circuit current density $\left(J_{\mathrm{SC}}\right)$ of $16.5 \mathrm{~mA} \mathrm{~cm}^{-2}$, open circuit voltage $\left(V_{\mathrm{OC}}\right)$ of $0.81 \mathrm{~V}$, and fill factor (FF) of 0.33 . The lower PCE $(3.90 \%)$ of the device based on 3,6-Cbz-EDOT was mainly due to the lower $J_{\mathrm{SC}}$ $\left(14.7 \mathrm{~mA} \mathrm{~cm}^{-2}\right)$, which would be reflected in the absorption range and hole mobility of the HTMs [43]. In addition, it was postulated that the deeper HOMO level of 2,7-Cbz-EDOT facilitated the hole extraction from the valence band of the perovskite layer [44]. Moreover, it should be noted that 2,7Cbz-EDOT outperforms the benchmark p-type semiconducting polymer, P3HT, despite almost the same HOMO levels.

The incident photon to current conversion efficiency (IPCE) spectra of the three devices were measured (Figure 3b). The perovskite nanocrystals strongly absorbed light over the entire visible range, and accordingly, the IPCE spectral shapes of all the devices were almost identical. This result indicates that light absorption by the hole-transporting polymers does not significantly contribute to the photocurrent generation and the main role of the polymers is hole transport. The peak intensities of the IPCE spectra obtained from the devices based on 3,6-CbzEDOT and 2,7-Cbz-EDOT exceeded 0.70 in the wavelength range of $380-510 \mathrm{~nm}$. This value is apparently higher than that of the device based on P3HT with the maximum IPCE peak intensity of 0.66 at $470 \mathrm{~nm}$, as supported by the $J_{\mathrm{SC}}$ values obtained from the $J-V$ curves. All these results strongly suggest that the Cbz-EDOT polymers are better HTMs in the PSCs as compared to P3HT.

\section{Dynamic impedance spectroscopy}

Dynamic impedance spectroscopy was used to determine the charge-transporting parameters in the PSCs, such as the chemical capacitance, recombination resistance, and charge conductivity [45]. It is known that the performance metrics of the HTMs in the PSCs can be partially explained by these parameters. For example, it was suggested that FF is associated with the series resistance $\left(R_{\mathrm{S}}\right)$, and a low $R_{\mathrm{S}}$ is required to construct high performance photovoltaic devices [46]. The dynamic impedance spectra of the PSCs with different HTMs over the frequency range of $1 \mathrm{~Hz}$ to $1 \mathrm{MHz}$ are shown in Figure 4, and the $R_{\mathrm{S}}$ values are listed in Table 2. It was found that the order of $R_{\mathrm{S}}$ is $R_{\mathrm{S}}(\mathrm{P} 3 \mathrm{HT})<R_{\mathrm{S}}(2,7-\mathrm{Cbz}-\mathrm{EDOT})<R_{\mathrm{S}}(3,6-\mathrm{Cbz}-\mathrm{EDOT})$, which is in good agreement with the inverse order of the FFs of the corresponding PSCs (vide supra).

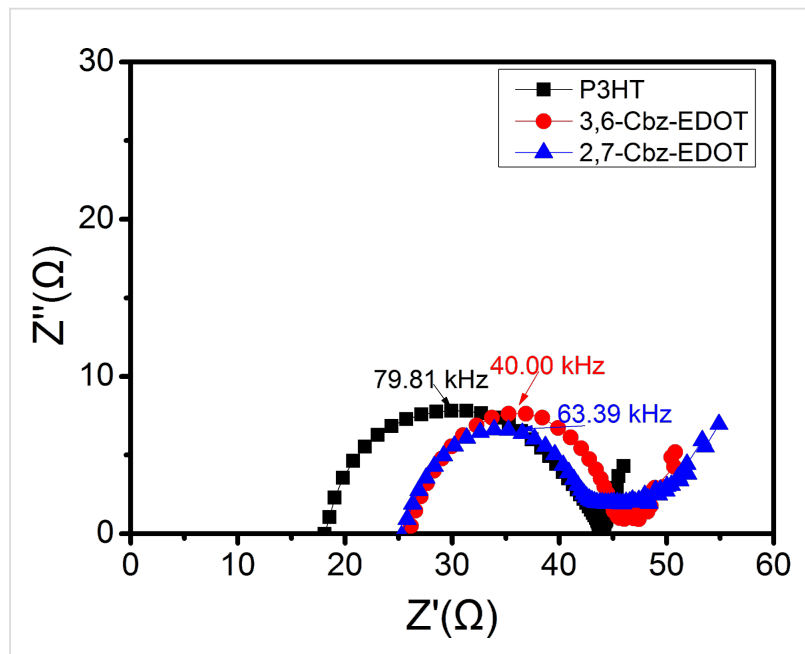

Figure 4: Impedance spectroscopy characterization of the PSCs with different HTMs over the frequency range from $1 \mathrm{~Hz}$ to $1 \mathrm{MHz}$ at $0 \mathrm{~V}$ bias voltage under simulated AM1.5G illumination $\left(100 \mathrm{~mW} \mathrm{~cm}^{-2}\right)$.

On the other hand, the effective carrier lifetime or time constant $(\tau)$ is related to the recombination of an electron and a hole at the interfaces between the perovskite and $\mathrm{TiO}_{2}$ or hole-transporting layers. This parameter can be calculated according to Equation 2 [47]:

$$
\tau=1 /(2 \pi f)
$$

where $f$ is the maximum frequency derived from the semicircle of the impedance spectra, also known as the character frequency. The calculated $\tau$ values are listed in Table 2 . The device based on 3,6-Cbz-EDOT displayed the longest lifetime of $3.98 \mu \mathrm{s}$, which is almost twice as high as that of the device based on P3HT. This result can be explained by the LUMO levels of the HTMs [48]. Since 3,6-Cbz-EDOT has the highest LUMO level of $-2.50 \mathrm{eV}$, the electron-blocking ability of this

Table 2: Photovoltaic parameters of PSCs based on 3,6-Cbz-EDOT, 2,7-Cbz-EDOT, and P3HT.

\begin{tabular}{lccccc} 
HTM & $J_{\mathrm{SC}}\left(\mathrm{mA} / \mathrm{cm}^{2}\right)^{\mathrm{a}}$ & $V_{\mathrm{Oc}}(\mathrm{V})^{\mathrm{a}}$ & $\mathrm{FF}^{\mathrm{a}}$ & PCE $(\%)^{\mathrm{a}}$ & $R_{\mathrm{S}}(\Omega)^{\mathrm{b}}$ \\
\hline 3,6-Cbz-EDOT & 14.7 & 0.80 & 0.32 & 3.90 & 26.51 \\
2,7-Cbz-EDOT & 16.5 & 0.81 & 0.33 & 4.47 & 25.98 \\
P3HT & 12.8 & 0.79 & 0.41 & 4.14 & 17.94 \\
\hline
\end{tabular}

${ }^{a} A$ verage values from 10 devices with the sample area of $0.75 \mathrm{~cm}^{2}$ under illumination of $100 \mathrm{~mW} \mathrm{~cm}^{-2}$. ${ }^{\mathrm{b}}$ Average values from 10 devices with the $\mathrm{DC}$ potential of $0 \mathrm{~V}, \mathrm{AC}$ amplitude of $10 \mathrm{mV}$, and frequency of $1 \mathrm{~Hz}$ to $1 \mathrm{MHz}$ under illumination of $100 \mathrm{~mW} \mathrm{~cm}^{-2}$. 
hole-transporting layer is more significant than the other two polymer layers. There is indeed a clear correlation between the $\tau$ values of the devices and the LUMO levels of the HTMs.

\section{Conclusion}

In summary, highly electron-rich donor-donor type polymers with the different carbazole connectivity patterns, i.e., 3,6-CbzEDOT and 2,7-Cbz-EDOT, were synthesized by the Pd-catalyzed Stille polycondensation. The HOMO/LUMO energy levels of these polymers were determined from the onset oxidation potentials and optical band gaps. Similar to the reported carbazole-based semiconducting polymers, 3,6-Cbz-EDOT had higher energy levels than 2,7-Cbz-EDOT. These Cbz-EDOT polymers were applied to the hole-transporting layer of PSCs, and the photovoltaic properties were investigated in comparison to that based on P3HT. The 2,7-Cbz-EDOT based device showed the higher PCE of $4.47 \%$ as compared to those based on 3,6-Cbz-EDOT and also P3HT. This was due to the deeper HOMO level and higher hole mobility, suggesting the importance of the molecular design regarding the carbazole connectivity. In addition, the IPCE spectra suggested the higher photocurrent generation of the device based on 2,7-Cbz-EDOT, which is associated with the $J_{\mathrm{SC}}$. Furthermore, the impedance spectroscopy characterization revealed that the carrier recombination of the devices based on the Cbz-EDOT polymers is effectively suppressed due to the prolonged carrier lifetime. It is worth noting that there is still a room for improvement of the carrier mobility and lifetime by the increase in the molecular weights of these polymers. Overall, the Cbz-EDOT polymers, especially 2,7-Cbz-EDOT, are solution-processable promising HTMs of the PSCs.

\section{Experimental Materials}

3,6-Dibromo-9-(2-ethylhexyl)carbazole [49] and 2,7-dibromo9-(2-ethylhexyl)carbazole [27] were prepared according to the reported literature procedure. Commercially available solvents and reagents were used without further purification unless stated otherwise. P3HT (regioregular) was purchased from Aldrich.

\section{Synthesis}

\section{Synthesis of 9-(2-ethylhexyl)-3,6-bis(tri- $n$-butyl- stannyl)carbazole (1)}

To a solution of 3,6-dibromo-9-(2-ethylhexyl)carbazole $(0.360 \mathrm{~g}, 0.800 \mathrm{mmol})$ in THF $(10 \mathrm{~mL}), n$-butyllithium (1.6 M, $1.20 \mathrm{~mL}$ ) in THF was added dropwise at $-78{ }^{\circ} \mathrm{C}$ under Ar. After stirring for $30 \mathrm{~min}, 0.88 \mathrm{~mL}$ of chlorotributyltin $(1.04 \mathrm{~g}$, $2.00 \mathrm{mmol}$ ) were injected by a syringe. Then, the mixture was warmed to $0{ }^{\circ} \mathrm{C}$ and stirred at this temperature for $30 \mathrm{~min}$. After the mixture was further warmed and stirred at room tempera- ture overnight, water was added and the organic layer was extracted with $\mathrm{CH}_{2} \mathrm{Cl}_{2}$ (3 times). The combined organic layer was dried over $\mathrm{MgSO}_{4}$. After filtration, the solvent was removed under reduced pressure and the crude product was purified by column chromatography $\left(\mathrm{SiO}_{2}, \mathrm{CHCl}_{3}\right)$, yielding the desired product $1(0.338 \mathrm{~g}, 48 \%) .{ }^{1} \mathrm{H} \mathrm{NMR}\left(300 \mathrm{MHz}, \mathrm{CDCl}_{3}\right)$ $\delta 8.22(\mathrm{~s}, 2 \mathrm{H}), 7.55(\mathrm{~d}, J=7.9 \mathrm{~Hz}, 2 \mathrm{H}), 7.42(\mathrm{~d}, J=8.0 \mathrm{~Hz}$, $2 \mathrm{H}), 4.17(\mathrm{dd}, J=7.2,3.8 \mathrm{~Hz}, 2 \mathrm{H}), 2.10(\mathrm{~s}, 1 \mathrm{H}), 1.64(\mathrm{~d}, J=7.6$ $\mathrm{Hz}, 12 \mathrm{H}), 1.42(\mathrm{dd}, J=14.6,7.3 \mathrm{~Hz}, 21 \mathrm{H}), 1.26-1.09$ (m, 12H), $0.95 \mathrm{ppm}(\mathrm{dd}, J=8.4,6.2 \mathrm{~Hz}, 25 \mathrm{H}) ;{ }^{13} \mathrm{C} \mathrm{NMR}(75 \mathrm{MHz}$, $\left.\mathrm{CDCl}_{3}\right) \delta 140.85,133.09,129.25,128.03,122.81,108.78$, $47.15,39.37,30.86,29.07,28.74,27.71,27.32,26.96,26.73$, 24.27, 22.96, 17.37, 13.94, 13.58, 13.48, 10.75, 9.59 ppm; FTIR (neat) $v: 2955,2923,2852,2361,1798,1652,1614,1581$, 1462, 1419, 1376, 1342, 1276, 1258, 1218, 1143, 1063, 1014, $961,867,794,749,698,679,654,624,607 \mathrm{~cm}^{-1}$; MALDI-TOF MS $\left(M_{\mathrm{w}}=859.4\right): m / z=860.7\left([\mathrm{M}+\mathrm{H}]^{+}\right)$.

\section{Synthesis of 9-(2-ethylhexyl)-2,7-bis(tri-n-butyl- stannyl)carbazole (2)}

To a solution of 2,7-dibromo-9-(2-ethylhexyl)carbazole $(0.437 \mathrm{~g}, 1.00 \mathrm{mmol})$ in THF $(10 \mathrm{~mL}), n$-butyllithium $(1.6 \mathrm{M}$, $1.50 \mathrm{~mL}$ ) in THF was added dropwise at $-78{ }^{\circ} \mathrm{C}$ under Ar. After stirring for $30 \mathrm{~min}, 1.10 \mathrm{~mL}$ of chlorotributyltin $(1.30 \mathrm{~g}$, $2.50 \mathrm{mmol}$ ) was injected by a syringe. Then, the mixture was warmed to $0{ }^{\circ} \mathrm{C}$ and stirred at this temperature for $30 \mathrm{~min}$. After the mixture was further warmed and stirred at room temperature overnight, water was added and the organic layer was extracted with $\mathrm{CH}_{2} \mathrm{Cl}_{2}$ (3 times). The combined organic layer was dried over $\mathrm{MgSO}_{4}$. After filtration, the solvent was removed under reduced pressure and the crude product was purified by column chromatography $\left(\mathrm{SiO}_{2}, \mathrm{CHCl}_{3}\right)$, yielding the desired product $2(0.407 \mathrm{~g}, 46 \%) .{ }^{1} \mathrm{H} \mathrm{NMR}\left(300 \mathrm{MHz}, \mathrm{CDCl}_{3}\right)$ $\delta 8.05(\mathrm{~d}, J=7.5 \mathrm{~Hz}, 2 \mathrm{H}), 7.48(\mathrm{~s}, 2 \mathrm{H}), 7.28(\mathrm{~d}, J=7.6 \mathrm{~Hz}$, $2 \mathrm{H}), 4.18(\mathrm{~d}, J=6.5 \mathrm{~Hz}, 2 \mathrm{H}), 2.05(\mathrm{~s}, 1 \mathrm{H}), 1.76-1.49(\mathrm{~m}, 12 \mathrm{H})$, $1.36(\mathrm{dd}, J=14.7,7.3 \mathrm{~Hz}, 21 \mathrm{H}), 1.12(\mathrm{dd}, J=9.6,6.7 \mathrm{~Hz}$, $12 \mathrm{H}), 0.89 \mathrm{ppm}(\mathrm{dd}, J=9.2,5.3 \mathrm{~Hz}, 25 \mathrm{H}) ;{ }^{13} \mathrm{C} \mathrm{NMR}(75 \mathrm{MHz}$, $\left.\mathrm{CDCl}_{3}\right) \delta 140.90,139.17,126.57,123.19,119.98,117.02$, 47.31, 40.02, 31.53, 29.49, 27.73, 24.82, 23.38, 14.34, 14.00, 11.21, 10.08, 7.84 ppm; FTIR (neat) v: 2955, 2923, 2870, 2852, $1485,1458,1441,1415,1376,1339,1319,1250,1200,1146$, $1071,996,962,911,860,826,814,794,741,723,710,695$, $653,633,616 \mathrm{~cm}^{-1}$; MALDI-TOF MS $\left(M_{\mathrm{W}}=859.4\right): \mathrm{m} / \mathrm{z}=$ $860.5\left([\mathrm{M}+\mathrm{H}]^{+}\right)$.

\section{Synthesis of 3,6-Cbz-EDOT}

Analogously to the description in [50], a solution of 1 ( $0.337 \mathrm{~g}$, $0.400 \mathrm{mmol}$ ) and 2,5-dibromo-3,4-ethylenedioxythiophene $(0.117 \mathrm{~g}, 0.400 \mathrm{mmol})$ in toluene $(5 \mathrm{~mL})$ was degassed with nitrogen for $15 \mathrm{~min}$. $\mathrm{Pd}_{2}(\mathrm{dba})_{3}(0.010 \mathrm{~g}, 0.011 \mathrm{mmol})$ and $\mathrm{P}(o \text {-tolyl })_{3}(0.015 \mathrm{~g}, 0.049 \mathrm{mmol})$ were added. The reaction 
mixture was further degassed and then heated to $110^{\circ} \mathrm{C}$ for $48 \mathrm{~h}$. After cooling to room temperature, the mixture was poured into methanol. The precipitate was collected and washed with methanol and hexane. The precipitate was subsequently subjected to Soxhlet extraction with chloroform. The solvent was removed under reduced pressure, yielding 3,6-Cbz-EDOT $(0.10 \mathrm{~g}, 60 \%)$. GPC (THF): $M_{\mathrm{n}}=2.0 \mathrm{~kg} \mathrm{~mol}^{-1}, M_{\mathrm{w}} / M_{\mathrm{n}}=1.5$; ${ }^{1} \mathrm{H}$ NMR (300 MHz, $\mathrm{CDCl}_{3}$ ) $\delta 8.50-8.37$ (br, Ar-H), 8.00-7.73 (br, Ar-H), 7.54-7.07 (br, Ar-H), 4.64-4.24 (br, $\mathrm{CH}_{2}$ ), 4.24-3.85 (br, $\mathrm{OCH}_{2}$ ), 2.04 (br, $\mathrm{CH}$ ), 1.50-1.16 (br, $\mathrm{CH}_{2}$ ), 1.01-0.70 ppm (br, $\mathrm{CH}_{3}$ ); FTIR (neat) v: 2955, 2921, 2852, $1581,1463,1419,1375,1341,1276,1258,1219,1142,1063$, $1015,961,868,795,749,699,653,625,607 \mathrm{~cm}^{-1}$.

\section{Synthesis of 2,7-Cbz-EDOT}

Analogously to the description in [50], a solution of 2 (0.392 g, $0.450 \mathrm{mmol})$ and 2,5-dibromo-3,4-ethylenedioxythiophene $(0.136 \mathrm{~g}, 0.450 \mathrm{mmol})$ in toluene $(5 \mathrm{~mL})$ was degassed with nitrogen for $15 \mathrm{~min} . \mathrm{Pd}_{2}(\mathrm{dba})_{3}(0.010 \mathrm{~g}, 0.011 \mathrm{mmol})$ and $\mathrm{P}(o \text {-tolyl })_{3}(0.015 \mathrm{~g}, 0.049 \mathrm{mmol})$ were added. The reaction mixture was further degassed and then heated to $110{ }^{\circ} \mathrm{C}$ for $48 \mathrm{~h}$. After cooling to room temperature, the mixture was poured into methanol. The precipitate was collected and washed with methanol and hexane. The precipitate was subsequently subjected to Soxhlet extraction with chloroform. The solvent was removed under reduced pressure, yielding 2,7-Cbz-EDOT $(0.13 \mathrm{~g}, 78 \%)$. GPC (THF): $M_{\mathrm{n}}=3.0 \mathrm{~kg} \mathrm{~mol}^{-1}, M_{\mathrm{w}} / M_{\mathrm{n}}=1.4$; ${ }^{1} \mathrm{H}$ NMR $\left(300 \mathrm{MHz}, \mathrm{CDCl}_{3}\right) \delta 8.22-7.97$ (br, Ar-H), 7.97-7.79 (br, Ar-H), 7.74-7.47 (br, Ar-H), 4.47 (br, $\mathrm{CH}_{2}$ ), 4.35-3.92 (br, O- $\mathrm{CH}_{2}$ ), 2.14 (br, CH), 1.62-1.17 (br, $\mathrm{CH}_{2}$ ), 1.12-0.67 ppm (br, $\mathrm{CH}_{3}$ ); FTIR (neat) v: 2955, 2925, 2870, 1599, 1558, 1482, 1455, 1428, 1361, 1332, 1252, 1216, 1196, 1168, 1120, 1088, $997,935,906,860,801,727,720,700,675,649,633,625,618$ $\mathrm{cm}^{-1}$.

\section{General measurements}

${ }^{1} \mathrm{H}$ NMR and ${ }^{13} \mathrm{C}$ NMR spectra were measured on a JEOL model AL300 spectrometer at $20^{\circ} \mathrm{C}$. Chemical shifts are reported in ppm downfield from $\mathrm{SiMe}_{4}$, using the solvent's residual signal as an internal reference. Fourier transform infrared (FTIR) spectra were recorded on a JASCO FT/IR-4100 spectrometer in the range from 4000 to $600 \mathrm{~cm}^{-1}$. MALDI-TOF mass spectra were measured on a Shimadzu/ Kratos AXIMA-CFR mass spectrometer equipped with nitrogen laser $(\lambda=337 \mathrm{~nm})$ and pulsed ion extraction, which was operated in a linear-positive ion mode at an accelerating potential of $20 \mathrm{kV}$. Dichloromethane solutions containing $1 \mathrm{~g} \mathrm{~L}^{-1}$ of a sample, $10 \mathrm{~g} \mathrm{~L}^{-1}$ of dithranol, and $1 \mathrm{~g} \mathrm{~L}^{-1}$ of sodium trifluoroacetate were mixed at the ratio of $1: 1: 1$, and $1 \mathrm{~mL}$ aliquot of this mixture was deposited onto a sample target plate. Gel permeation chromatography (GPC) was measured on a JASCO
GULLIVER 1500 equipped with a pump (PU-2080 Plus), an absorbance detector (RI-2031 Plus), and two Shodex GPC KF-803 columns $(8.0 \mathrm{~mm}$ I.D. $\times 300 \mathrm{~mm} \mathrm{~L})$ based on a conventional calibration curve using polystyrene standards. Tetrahydrofuran $\left(40^{\circ} \mathrm{C}\right)$ was used as a carrier solvent at the flow rate

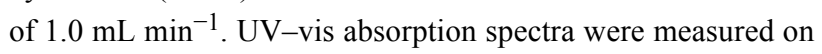
a JASCO V-670 spectrophotometer. Polymer thin films were prepared on an ITO glass (about $0.8 \times 2.5 \mathrm{~cm}^{2}$ ) by spraycoating of polymer solutions $\left(5.0 \mathrm{~g} \mathrm{~L}^{-1}\right.$ in $\left.\mathrm{CH}_{2} \mathrm{Cl}_{2}\right)$. Electrochemistry measurements were carried out on a BAS electrochemical analyzer model $612 \mathrm{C}$ at $25{ }^{\circ} \mathrm{C}$ in dehydrated $\mathrm{CH}_{3} \mathrm{CN}$ containing $0.1 \mathrm{M}\left(n-\mathrm{C}_{4} \mathrm{H}_{9}\right)_{4} \mathrm{NPF}_{6}$ in the three electrode cell. The working, reference, and auxiliary electrodes were a glassy carbon electrode, $\mathrm{Ag} / \mathrm{Ag}^{+} / \mathrm{CH}_{3} \mathrm{CN} /\left(n-\mathrm{C}_{4} \mathrm{H}_{9}\right)_{4} \mathrm{NPF}_{6}$, and a $\mathrm{Pt}$ wire, respectively.

\section{Fabrication and measurements of perovskite solar cells}

Fluorine-doped tin oxide (FTO)-coated glass substrates (20 $\Omega$ per square) were patterned to fabricate the solar cells. These substrates were successively washed by ultrasonication in water, acetone, and isopropyl alcohol for $10 \mathrm{~min}$ each, and then dried in a stream of dry air. The washed substrates were further treated with a UV-O 3 cleaner (Filgen, Model UV253E) for $20 \mathrm{~min}$. The electron-accepting $\mathrm{TiO}_{2}$ compact layer was spincoated (1500 rpm for $30 \mathrm{~s}$ ) from a mildly acidic (after addition of $12 \mu \mathrm{M} \mathrm{HCl}$ ) solution of titanium(IV) isopropoxide in anhydrous ethanol and sintered at $120{ }^{\circ} \mathrm{C}$ for $10 \mathrm{~s}$. The mesoporous $\mathrm{TiO}_{2}$ layer composed of $20 \mathrm{~nm}$-sized particles was deposited by spin-coating at $4000 \mathrm{rpm}$ for $30 \mathrm{~s}$ using a commercial $\mathrm{TiO}_{2}$ paste (PST-18NR, JGC Catalysts and Chemicals Ltd.) diluted in ethanol $\left(2: 7\right.$, weight ratio). After drying at $120^{\circ} \mathrm{C}$, the $\mathrm{TiO}_{2}$ films were gradually heated to $500{ }^{\circ} \mathrm{C}$, baked at this temperature for $20 \mathrm{~min}$, and cooled to room temperature. The mesoporous $\mathrm{TiO}_{2}$ films were infiltrated with $\mathrm{PbI}_{2}$ by spin-coating a $\mathrm{PbI}_{2}$ solution in DMF $\left(465 \mathrm{~g} \mathrm{~L}^{-1}\right)$ at $80{ }^{\circ} \mathrm{C}$. After drying, the films were dipped in a solution of $\mathrm{CH}_{3} \mathrm{NH}_{3} \mathrm{I}$ in 2-propanol $\left(10 \mathrm{~g} \mathrm{~L}^{-1}\right)$ for $20 \mathrm{~s}$ and rinsed with 2-propanol. After drying, the hole transporting materials were deposited by spin-coating a solution of P3HT, 3,6-Cbz-EDOT, or 2,7-Cbz-EDOT in chlorobenzene $\left(7.82 \mathrm{~g} \mathrm{~L}^{-1}\right)$. All hole-transporting layers were dried in the dark. The thickness of the hole-transporting layers was about $30 \mathrm{~nm}$. Finally, gold $(80 \mathrm{~nm})$ was thermally evaporated on the top of the device to form the back contact.

The current density-voltage $(J-V)$ characteristics, incident photon current efficiency (IPCE), and dynamic impedance spectroscopy of the fabricated perovskite solar cells were evaluated. The active area of the devices was $0.75 \mathrm{~cm}^{2}$. The $J-V$ curves were measured on a CEP-2000RS (Bunko-Keiki Co., Ltd.) under illumination of a solar simulator with a light intensity of 
$100 \mathrm{~mW} \mathrm{~cm}^{-2}$ (AM1.5). IPCE measurements were carried out using a Xenon lamp attached to a monochromator. Two focusing lenses were used to focus the monochromatic light to the active area of solar cells. Dynamic impedance spectroscopy was measured on an SI1260 Impedance/Gain-Phase Analyzer and SI1286 Electrochemical Interface (Solartron) at $0 \mathrm{~V}$ bias voltage and a frequency range from $1 \mathrm{~Hz}$ and $1 \mathrm{MHz}$ with an AC amplitude of $10 \mathrm{~mA}$ under illumination of simulated solar AM1.5 global light at $100 \mathrm{~mW} \mathrm{~cm}{ }^{-2}$. A Z-View Analyst software was used to model the Nyquist plots obtained from the impedance measurements.

\section{Supporting Information}

\section{Supporting Information File 1}

Synthesis of carbazole derivatives, ${ }^{1} \mathrm{H}$ NMR and IR spectra of the polymers, and OFET performances.

[http://www.beilstein-journals.org/bjoc/content/ supplementary/1860-5397-12-134-S1.pdf]

\section{Acknowledgements}

This work was supported by JSPS KAKENHI (Grant Number 26620173), Kurata Memorial Hitachi Science and Technology Foundation, Tokuyama Science Foundation, and the Support for Tokyotech Advanced Researchers (T.M.) and the Tochigi Industrial Promotion Center (T.K).

\section{References}

1. Kojima, A.; Teshima, K.; Shirai, Y.; Miyasaka, T. J. Am. Chem. Soc. 2009, 131, 6050-6051. doi:10.1021/ja809598r

2. Liu, M.; Johnston, M. B.; Snaith, H. J. Nature 2013, 501, 395-398. doi:10.1038/nature12509

3. Zhou, H.; Chen, Q.; Li, G.; Luo, S.; Song, T.-b.; Duan, H.-S.; Hong, Z.; You, J.; Liu, Y.; Yang, Y. Science 2014, 345, 542-546. doi:10.1126/science.1254050

4. Rakstys, K.; Abate, A.; Dar, M. I.; Gao, P.; Jankauskas, V.; Jacopin, G.; Kamarauskas, E.; Kazim, S.; Ahmad, S.; Grätzel, M.; Nazeeruddin, M. K. J. Am. Chem. Soc. 2015, 137, 16172-16178. doi:10.1021/jacs.5b11076

5. Huang, C.; Fu, W.; Li, C.-Z.; Zhang, Z.; Qiu, W.; Shi, M.; Heremans, P.; Jen, A. K.-Y.; Chen, H. J. Am. Chem. Soc. 2016, 138, 2528-2531. doi:10.1021/jacs.6b00039

6. Jeon, N. J.; Lee, J.; Noh, J. H.; Nazeeruddin, M. K.; Grätzel, M.; Seok, S. I. J. Am. Chem. Soc. 2013, 135, 19087-19090. doi:10.1021/ja410659k

7. Bi, D.; Yang, L.; Boschloo, G.; Hagfeldt, A.; Johansson, E. M. J. J. Phys. Chem. Lett. 2013, 4, 1532-1536. doi:10.1021/jz400638x

8. Margulis, G. Y.; Christoforo, M. G.; Lam, D.; Beiley, Z. M.; Bowring, A. R.; Bailie, C. D.; Salleo, A.; McGehee, M. D. Adv. Energy Mater. 2013, 3, 1657-1663. doi:10.1002/aenm.201300660

9. Jeon, N. J.; Lee, H. G.; Kim, Y. C.; Seo, J.; Noh, J. H.; Lee, J.; Seok, S. I. J. Am. Chem. Soc. 2014, 136, 7837-7840. doi:10.1021/ja502824c
10. Liu, J.; Pathak, S.; Stergiopoulos, T.; Leijtens, T.; Wojciechowski, K.; Schumann, S.; Kausch-Busies, N.; Snaith, H. J. J. Phys. Chem. Lett. 2015, 6, 1666-1673. doi:10.1021/acs.jpclett.5b00545

11. Di Giacomo, F.; Razza, S.; Matteocci, F.; D'Epifanio, A.; Licoccia, S.; Brown, T. M.; Di Carlo, A. J. Power Sources 2014, 251, 152-156. doi:10.1016/j.jpowsour.2013.11.053

12. Kwon, Y. S.; Lim, J.; Yun, H.-J.; Kim, Y.-H.; Park, T. Energy Environ. Sci. 2014, 7, 1454-1460. doi:10.1039/c3ee44174a

13. Ryu, S.; Noh, J. H.; Jeon, N. J.; Kim, Y. C.; Yang, W. S.; Seo, J.; Seok, S. I. Energy Environ. Sci. 2014, 7, 2614-2618. doi:10.1039/C4EE00762J

14. Grazulevicius, J. V.; Strohriegl, P.; Pielichowski, J.; Pielichowski, K. Prog. Polym. Sci. 2003, 28, 1297-1353. doi:10.1016/S0079-6700(03)00036-4

15. Morin, J.-F.; Leclerc, M.; Adès, D.; Siove, A. Macromol. Rapid Commun. 2005, 26, 761-778. doi:10.1002/marc.200500096

16. Blouin, N.; Leclerc, M. Acc. Chem. Res. 2008, 41, 1110-1119. doi:10.1021/ar800057k

17. Li, J.; Grimsdale, A. C. Chem. Soc. Rev. 2010, 39, 2399-2410. doi:10.1039/b915995a

18. Beaupré, S.; Boudreault, P.-L. T.; Leclerc, M. Adv. Mater. 2010, 22, E6-E27. doi:10.1002/adma.200903484

19. Boudreault, P.-L. T.; Beaupré, S.; Leclerc, M. Polym. Chem. 2010, 1, 127-136. doi:10.1039/B9PY00236G

20. Wong, W.-Y.; Harvery, R. D. Macromol. Rapid Commun. 2010, 31, 671-713. doi:10.1002/marc.200900690

21. Beaupré, S.; Leclerc, M. J. Mater. Chem. A 2013, 1, 11097-11105. doi:10.1039/c3ta12420g

22. Tao, X.-T.; Zhang, Y.-D.; Wada, T.; Sasabe, H.; Suzuki, H.; Watanabe, T.; Miyata, S. Adv. Mater. 1998, 10, 226-230. doi:10.1002/(SICI)1521-4095(199802)10:3<226::AID-ADMA226>3.0.C O;2-E

23. Michinobu, T.; Okoshi, K.; Osako, H.; Kumazawa, H.; Shigehara, K. Polymer 2008, 49, 192-199. doi:10.1016/j.polymer.2007.11.022

24. Cai, B.; Xing, Y.; Yang, Z.; Zhang, W.-H.; Qiu, J. Energy Environ. Sci. 2013, 6, 1480-1485. doi:10.1039/c3ee40343b

25. Dumur, F. Org. Electron. 2015, 25, 345-361. doi:10.1016/j.orgel.2015.07.007

26. Morin, J.-F.; Leclerc, M. Macromolecules 2001, 34, 4680-4682. doi: $10.1021 / \mathrm{ma} 010152 \mathrm{u}$

27. Dierschke, F.; Grimsdale, A. C.; Müllen, K. Synthesis 2003, 2470-2472. doi:10.1055/s-2003-42418

28. Blouin, N.; Michaud, A.; Wakim, S.; Boudreault, P.-L. T.; Leclerc, M.; Vercelli, B.; Zecchin, S.; Zotti, G. Macromol. Chem. Phys. 2006, 207, 166-174. doi:10.1002/macp.200500423

29. Leclerc, N.; Michaud, A.; Sirois, K.; Morin, J.-F.; Leclerc, M. Adv. Funct. Mater. 2006, 16, 1694-1704. doi:10.1002/adfm.200600171

30. Blouin, N.; Michaud, A.; Gendron, D.; Wakim, S.; Blair, E.; Neagu-Plesu, R.; Belletête, M.; Durocher, G.; Tao, Y.; Leclerc, M. J. Am. Chem. Soc. 2008, 130, 732-742. doi:10.1021/ja0771989

31. Aïch, R. B.; Blouin, N.; Bouchard, A.; Leclerc, M. Chem. Mater. 2009, 21, 751-757. doi:10.1021/cm8031175

32. Michinobu, T.; Kumazawa, H.; Otsuki, E.; Usui, H.; Shigehara, K. J. Polym. Sci., Part A: Polym. Chem. 2009, 47, 3880-3891. doi:10.1002/pola.23454

33. Ma, Z.; Chen, L.; Ding, J.; Wang, L.; Jing, X.; Wang, F. Adv. Mater. 2011, 23, 3726-3729. doi:10.1002/adma.201102140 
34. Hahm, S. G.; Lee, T. J.; Kim, D. M.; Kwon, W.; Ko, Y.-G.; Michinobu, T.; Ree, M. J. Phys. Chem. C 2011, 115, 21954-21962. doi:10.1021/jp207211e

35. Lombeck, F.; Komber, H.; Sepe, A.; Friend, R. H.; Sommer, M. Macromolecules 2015, 48, 7851-7860. doi:10.1021/acs.macromol.5b01845

36. Berns, B.; Tieke, B. Polym. Chem. 2015, 6, 4887-4901. doi:10.1039/C5PY00713E

37. Li, W.; Michinobu, T. Polym. Chem. 2016, 7, 3165-3171. doi:10.1039/C6PY00381H Note that 3, 6-Cbz-EDOT was previously synthesized by direct arylation polycondensation.

38. Bucinskas, A.; Bagdziunas, G.; Tomkeviciene, A.; Volynyuk, D.; Kostiv, N.; Gudeika, D.; Jankauskas, V.; Rutkis, M.; Grazulevicius, J. V. RSC Adv. 2015, 5, 49577-49589. doi:10.1039/C5RA09161F

39. Zhu, Z.; Bai, Y.; Lee, H. K. H.; Mu, C.; Zhang, T.; Zhang, L.; Wang, J.; Yan, H.; So, S. K.; Yang, S. Adv. Funct. Mater. 2014, 24, 7357-7365. doi:10.1002/adfm.201401557

40. Cho, S.; Seo, J. H.; Park, S. H.; Beaupré, S.; Leclerc, M.; Heeger, A. J. Adv. Mater. 2010, 22, 1253-1257. doi:10.1002/adma.200903420

41. Huang, C.; Sartin, M. M.; Cozzuol, M.; Siegel, N.; Barlow, S.; Perry, J. W.; Marder, S. R. J. Phys. Chem. A 2012, 116, 4305-4317. doi:10.1021/jp3006712

42. Kim, J. Y.; Kim, S. H.; Lee, H.-H.; Lee, K.; Ma, W.; Gong, X.; Heeger, A. J. Adv. Mater. 2006, 18, 572-576. doi:10.1002/adma.200501825

43. Dubey, A.; Adhikari, N.; Venkatesan, S.; Gu, S.; Khatiwada, D.; Wang, Q.; Mohammad, L.; Kumar, M.; Qiao, Q. Sol. Energy Mater. Sol. Cells 2016, 145, 193-199. doi:10.1016/j.solmat.2015.10.008

44. Chen, W.; Bao, X.; Zhu, Q.; Zhu, D.; Quu, M.; Sun, M.; Yang, R. J. Mater. Chem. C 2015, 3, 10070-10073. doi:10.1039/C5TC01856K

45. Bisquert, J.; Bertoluzzi, L.; Mora-Sero, I.; Garcia-Belmonte, G. J. Phys. Chem. C 2014, 118, 18983-18991. doi:10.1021/jp5062144

46. Juarez-Perez, E. J.; Wußler, M.; Fabregat-Santiago, F.; Lakus-Wollny, K.; Mankel, E.; Mayer, T.; Jaegermann, W.; Mora-Sero, I. J. Phys. Chem. Lett. 2014, 5, 680-685. doi:10.1021/jz500059v

47. Zhang, J.; Hu, Z.; Huang, L.; Yue, G.; Liu, J.; Lu, X.; Hu, Z.; Shang, M.; Han, L.; Zhu, Y. Chem. Commun. 2015, 51, 7047-7050. doi:10.1039/C5CC00128E

48. Xiao, Y.; Han, G.; Wu, J.; Lin, J.-Y. J. Power Sources 2016, 306, 171-177. doi:10.1016/j.jpowsour.2015.12.003

49. Jung, S.-H.; Kim, H. K.; Kim, S.-H.; Kim, Y. H.; Jeoung, S. C.; Kim, D. Macromolecules 2000, 33, 9277-9288. doi:10.1021/ma0003248

50. Li, W.; Michinobu, T. Macromol. Chem. Phys. 2016, 217, 863-870. doi:10.1002/macp.201500494

\section{License and Terms}

This is an Open Access article under the terms of the Creative Commons Attribution License

(http://creativecommons.org/licenses/by/2.0), which permits unrestricted use, distribution, and reproduction in any medium, provided the original work is properly cited.

The license is subject to the Beilstein Journal of Organic Chemistry terms and conditions:

(http://www.beilstein-journals.org/bjoc)

The definitive version of this article is the electronic one which can be found at:

doi:10.3762/bjoc. 12.134 